SEMBLANZAS 



\title{
DON ANTONIO ALCALÁ GALIANO Y LOS INICIOS DE LA ENSEÑANZA DEL DERECHO CONSTITUCIONAL EN ESPAÑA
}

\author{
ÁNGEL GARRORENA MORALES \\ Catedrático emérito de Derecho Constitucional \\ Universidad de Murcia
}

SUMARIO

I. La enseñanza del Derecho constitucional en España. Sus inicios fuera de la universidad.

II. Alcalá Galiano y los cursos de Derecho constitucional del Ateneo.

III. Sobre la personalidad de don Antonio Alcalá Galiano, profesor de Derecho constitucional. Sus rasgos fundamentales.

IV. El contenido de las lecciones.

\section{LA ENSEÑANZA DEL DERECHO CONSTITUCIONAL EN ESPAÑA. SUS INICIOS FUERA DE LA UNIVERSIDAD}

Trazar la semblanza de don Antonio Alcalá Galiano como profesor de Derecho Constitucional (o de Derecho Político Constitucional si nos acogemos a la denominación de la cátedra desde la cual imparte dicha disciplina) requiere que hagamos algunas consideraciones preliminares sin las cuales no se podría centrar de forma adecuada este retrato. Y ello por la sencilla razón de que, a diferencia de lo que sucede con los otros «docentes» cuyas semblanzas ya ha recogido y seguirá recogiendo Teoría y Realidad, ni don Antonio Alcalá Galiano es un profesor universitario sea cual sea el ángulo desde el que se le contemple, ni la cátedra desde la cual se dirige a sus alumnos tiene nada que ver con ninguna Universidad española. Que las cosas sean de esta manera se basa en el hecho de que los tiempos en los que dicha docencia se imparte son todavía unos tiempos muy singulares para 
nuestra disciplina ${ }^{1}$, singularidad que se incorpora a su enseñanza como uno de los datos más significativos de la misma y nos obliga a nosotros a dedicarle alguna atención en estas páginas primeras.

Por lo que hace al segundo de los datos antes citados, esto es, al hecho de que estas enseñanzas no se impartieran en alguna Universidad española sino en una sede muy distinta (de la condición «no docente» de Alcalá Galiano, hablaremos después) baste para entenderlo con recordar que cuando Alcalá Galiano ocupa por primera vez la cátedra de Derecho Político Constitucional del Ateneo en 1838 (más aún si pensamos en 1836, año en el que fue designado para ocuparla) la experiencia constitucional española es todavía muy corta e incipiente. De hecho, apenas cuenta con los dos años de efímera vigencia de la Constitución de Cádiz (1812-1814), prorrogados si se quiere con los tres convulsos años que aportó el Trienio liberal (1820-1823) y, una década después, ya muerto Fernando VII rey absoluto, con los cuatro años que añadieron el Estatuto Real —ni siquiera un texto constitucional en sentido estricto- y la recién promulgada Constitución de 1837 (1834-1838). A la postre, nueve efímeros años vividos con mucha pasión pero sin ninguna continuidad son todo el bagaje con el que cuenta dicha experiencia; los dos largos periodos autocráticos que la interrumpen, de seis años el primero producido tras la vuelta de Fernando VII en 1814, y de diez años el segundo al que conocemos justificadamente como «la década ominosa», así lo expresan bien a las claras. Se comprende, pues, que las viejas estructuras de las anquilosadas Universidades españolas, lentas y formalmente comprometidas — salvo excepciones - con los esquemas propios del Antiguo Régimen, no tuvieran tiempo ni impulso para adaptarse fácilmente a los nuevos contenidos de un Derecho Público que aún seguía explicándose mayoritariamente en sus aulas conforme a los patrones del tradicional derecho natural y de gentes, más influidos por los esquemas de Vattel o de Burlamaqui que por las ideas de Rousseau o de Siéyes, aunque éstas se filtraran a veces. El propio curso de Ramón Lázaro Dou ( «Instituciones del derecho público general de España»), publicado en 1800-1803, cuando ya en Italia y en otros países existían las primeras Cátedras de Constitución (Compagnoni di Luzzo en Ferrara y Alpruni en Pavía, 1797; Algerati en Bolonia, 1798; Fusinieri en Brera, 1799...), es buena prueba de ello.

1 Sobre los orígenes de la enseñanza de nuestra disciplina en España es un clásico el trabajo de Luís SÁNCHez Agesta, «Las primeras cátedras españolas de Derecho Constitucional», publicado en el n. ${ }^{\circ} 126$ de la Revista de Estudios Políticos, Madrid, 1962. Su lectura puede complementarse en nuestros días con el muy riguroso estudio de Joaquín VArela SuAnzes-Carpegna, «¿Qué ocurrió con la Ciencia del Derecho Constitucional en la España del siglo XIX?", hoy consultable en la recopilación de trabajos del autor Política y Constitución en España (1836-1847), Madrid, 2014, segunda edición, p. 161 y ss. Por mi parte, me he ocupado también de este tema, con algún detalle, en las primeras páginas de mi libro El Ateneo de Madrid y la teoría de la Monarquía Liberal (1836-1847), Madrid, 1974, p. 17 y ss. Vid. también Francisco Manuel García Costa, La Ciencia española del Derecho Político-constitucional en sus textos (1808-1939), Valencia, 2008; en especial, su estudio preliminar. Para un conocimiento más puntual de esta cuestión, me remito a la bibliografía citada en cualquiera de dichas obras. 
Según esto, el establecimiento de una cátedra específica de Derecho Constitucional en la Universidad española era algo bastante complicado en el contexto de aquellos años en los que la Constitución era todavía más un objeto de enriscado debate entre corrientes ideológicas que una norma comúnmente aceptada susceptible del analítico discurso académico. Y eso pese a que el artículo 386 de la Constitución de Cádiz ordenaba, ya en 1812, explicar «la Constitución de la Monarquía española en todas las Universidades y establecimientos literarios» y por mucho que el plan de estudios de 1821 contemplara, en desarrollo de tal previsión, la existencia de una asignatura de Derecho Público Constitucional en nuestras Facultades de Jurisprudencia. De hecho, este mandato apenas pudo tener cumplimiento en la realidad. Es cierto que durante este tiempo Ramón de Salas, profesor de la Universidad de Salamanca, llegó a publicar en 1821 unas Lecciones de Derecho Público Constitucional para las escuelas de España ${ }^{2}$, pero la brevedad del Trienio por una parte y las limitaciones de la mencionada obra tan bien comentadas por Joaquín Varela por otra, impiden darle excesiva trascendencia a este intento. Y cuando a partir de 1836 los planes de estudios de las Facultades de Jurisprudencia intentaron reaccionar finalmente frente a tal estado de cosas lo hicieron tímidamente y sin conceder ninguna autonomía a la materia constitucional: así, en el arreglo provisional de dicho plan de estudios aprobado en 1836 nuestra disciplina apareció diluida bajo la denominación genérica de Elementos de Derecho Público, y en el plan de 1842, donde sí constaba ya con su propia denominación, quedó unida, no obstante, como una misma asignatura a Economía política ${ }^{3}$.

En estas condiciones, pues, la enseñanza del Derecho Constitucional en España debió su primer impulso — no de manera única pero sí decisiva- a la iniciativa de la propia sociedad española. Son las instituciones culturales del momento, muchas de ellas de origen privado, las que asumen la tarea de explicar y difundir, primero con un contenido tan sólo divulgatorio, después con una mayor altura, los saberes conectados a la idea de Constitución. Así se fundó en Valencia

2 En efecto, sobre las Lecciones de RAmón DE SALAS tiene sentido recordar aquí el juicio que hace de las mismas JoAQUín VARELA en el trabajo anteriormente citado. Se trata — dice allí — de una obra de transición entre el siglo XVIII y el XIX en la que, pese a partir de los presupuestos propios de la teoría constitucional de los revolucionarios franceses, eso se hace con una cierta incapacidad para resolver desde ellos $-\mathrm{y}$ de acuerdo con ellos - las cuestiones que, en la segunda parte de la obra, le plantea nuestro Derecho Constitucional positivo, en aquel momento la Constitución de Cádiz. Vid., «¿Qué ocurrió...?, op. cit., pp. 169-170.

3 Esta relativa desatención institucional de la Universidad española hacia el Derecho Constitucional no impidió, no obstante, que existiera entre nuestra clase política y nuestra intelectualidad de aquella época un discreto conocimiento de la bibliografía comparada sobre la materia. Por mencionar lo mínimo, para estas fechas Marcial Antonio López ya había traducido, bien que de una manera bastante libre, el Curso de Política Constitucional de Benjamín Constant (Madrid, Imprenta de la Compañía, 1820, 3 vols.) y Bentham (Tratados de Legislación Civil y Penal, Madrid, 1821) y Destut de TraCy (Comentario sobre el Espíritu de las Leyes de Montesquieu, Madrid 1821) eran conocidos en las respectivas traducciones que de ambas obras había hecho Ramón de Salas. Con un valor menor, por tratarse de una obra bastante gris, pese al influjo que ejerció entre nosotros, hay que consignar aquí, asimismo, la traducción que en 1838 hizo F. Enciso Castrillón de los Elementos de Derecho Público y Político de Macarel, publicados por el autor en París en 1833. 
en 1814 la cátedra de Constitución servida por Nicolás Garely o en Madrid, en los reales Estudios de San Isidro, la regentada por Miguel García de la Madrid, y seis años más tarde — llegado el Trienio — la creada en Barcelona por la Junta de Comercio en 1820, ocupada por Eudaldo Jaumeandreu. Y con idéntico espíritu, aunque dentro de un proyecto mucho más ambicioso, surgieron, tras la muerte de Fernando VII en septiembre de 1833, las cátedras del Ateneo de Madrid, una de las cuales, especialmente cuidada, estuvo dedicada — por lo que aquí interesa- a explicar el «Derecho Político Constitucional».

Efectivamente, el Ateneo de Madrid nació hacia finales de $1835^{4}$ merced al impulso de otra entidad cultural bien conocida, la Sociedad Económica Matritense, la cual convocó para la noche del 31 de octubre de dicho año una reunión en la que acabó nombrándose una comisión formada por Olózaga, el Duque de Rivas, Mesonero Romanos y el propio Alcalá Galiano, entre otros, a la que se encomendó gestionar el permiso gubernativo necesario para la fundación de un Ateneo Científico, Literario y Artístico plenamente independiente de aquella Sociedad Económica que lo promovía y orientada a unos fines distintos de los de dicha Sociedad Económica Matritense, más comprometida con los «saberes prácticos» propios de su matriz ilustrada que con los «saberes liberales» característicos de los nuevos tiempos. Esos fines quedaron claros el mismo día de la inauguración del Ateneo celebrada el 6 de diciembre en el Palacio de la Concepción Jerónima, propiedad del Duque de Rivas, que fue su primer presidente. En dicha ocasión ya éste dejó marcada con nitidez cuál iba a ser la función cultural y casi ideológica que debía desempeñar el Ateneo dentro del contexto de aquella España liberal: «Estas saludables reuniones — dijo entonces el Duque de Rivas-, tan interesantes para la bumanidad, son propias sólo de los países donde rigen instituciones liberales y donde el gobierno representativo, con sus libres discusiones, con todas sus consecuencias y siguiendo siempre la senda de la opinión pública, encuentra su más firme apoyo en la educación moral de los ciudadanos...(...) Para pensar es indispensable ser libres. Las Academias y cuerpos científicos y literarios, tan pomposamente instituidos y dotados por Luís XIV (...) no ban sido, a mi juicio, tan útiles a la difusión del saber y a la saludable propagación de los conocimientos que civilizan y mejoran la especie bumana, como cualquiera de los clubs científicos o literarios que espontáneamente ban nacido en Inglaterra a la sombra benéfica de la libertad (...) ¡Felices los tiempos en que es dado a los hombres el reunirse libremente para promover la ilustración de sus semejantes, o para asegurar la libertad; $»^{5}$. Y algo no muy distinto es lo que vendría a confirmar, meses después, con su peculiar estilo, quien fuera el primer socio admitido tras los miembros

4 Durante el Trienio liberal ya existió un Ateneo Español cuyos Estatutos se firmaron el 14 de mayo de 1820, pero su vida fue lánguida y apenas se conservan noticias de él. Las copias que en 1870 sacara Gómez Molinero de sus Estatutos y de sus dos Reglamentos de 1820 y 1822 parecen ser los únicos documentos conservados.

5 Ateneo Científico y Literario. Sesión inaugural del 6 de diciembre de 1835. Madrid, 1835, Imprenta de Jordán. 
fundadores del Ateneo, don Mariano José de Larra, el cual escribiría, en un artículo destinado a comentar la inauguración de las primeras cátedras del instituto, que "persuadidos como estamos de que la inteligencia es la que ha de hacer en el mundo las revoluciones, la instalación de una cátedra es, a nuestros ojos, un hecho más importante que un triunfo militar, así como es mucho más lisonjero y ventajoso a la bumanidad convencer a un hombre que matarlo» ${ }^{6}$. Pues de eso se trataba, y eso es lo que hizo comentar a Edgar Quinet en su obra Mis vacaciones en España que «el Ateneo es el centro de la sociedad literaria de Madrid; figuraos — diría_ una institución libre en la que los personajes politicos más importantes se empeñan en dirigir, con cursos públicos, la educación de la opinión. Los señores Martínez de la Rosa, Olózaga y Pidal han sido sucesivamente sus presidentes. Intentan dominar al país por las ideas, único yugo que hasta abora no ha querido soportar» ${ }^{7}$.

En consonancia con ello, la actividad del Ateneo de Madrid se ordenó, según escribiría por entonces don Ramón Mesonero Romanos que fue su secretario, en tres zonas complementarias: como academia o reunión para el debate montó sus Secciones, como instituto de enseñanza mantuvo sus Cátedras y como círculo literario tuvo su Biblioteca y sus tertulias ${ }^{8}$. En particular, sus Cátedras fueron el vehículo fundamental para la difusión de esos nuevos saberes liberales que, según le oímos decir a Larra, hacen más útil para la humanidad convencer a un hombre que matarlo. Y, entre esas Cátedras, ninguna con una indicación mayor hacia tal cometido que la Cátedra de Derecho Político Constitucional, a la que, por tanto, no es de extrañar que el Ateneo dedicara su mayor atención comprometiendo para su servicio sus mejores medios. En concreto, las personas designadas sucesivamente para ocuparla, don Juan Donoso Cortés en sustitución de don Antonio Alcalá Galiano, el propio don Antonio Alcalá Galiano, significado ateneísta ${ }^{9}$, y don Francisco Pacheco, fueron extraídas de lo más ilustre de la intelectualidad moderada, lo que (sin perjuicio de que éste sea otro aspecto de la cuestión) sólo se entiende en todo su alcance si recordamos que el compromiso de esta institución cultural con el partido moderado fue, desde un principio, su verdadero plomo en el ala; en palabras del propio Mesonero Romanos, «su pecado original» ${ }^{10}$. Pero de todo ello pasamos a ocuparnos en los epígrafes siguientes.

6 Mariano José de Larra, Artículos completos, Edit. Aguilar, Madrid, 1961, p. 1437.

7 Edgar Quinet, Mis vacaciones en España, Madrid, edición de 1931, pp. 60-61.

8 Ramón Mesonero Romanos, Sociedades literarias y artísticas. El Ateneo. El Liceo, en el Seminario Pintoresco, n. ${ }^{\circ}$ 94, de 14 de enero de 1838, pp. 425-427.

9 Sobre la personalidad ateneísta de Alcalá Galiano baste recordar lo siguiente. Estuvo en la comisión de la Sociedad Económica Matritense encargada de gestionar en 1835 la fundación del Ateneo. Fue Presidente del Ateneo en tres etapas de su vida (1845-47, 1849-52 y 1862-65). Fue, asimismo, Presidente de su Sección de Ciencias Morales y Política en diversas ocasiones. Y, además de la cátedra de Derecho Político Constitucional, regentó alguna otra, como tendremos ocasión de ver. En fin, don BENITo Pérez GaLdós, en sus Episodios Nacionales, ha recordado la figura de don Antonio Alcalá Galiano, ya viejo, consumiendo sus horas en la biblioteca del Ateneo rodeado de admiradores que todavía atendían su palabra y buscaban su criterio. Vid «Prim» en Obras completas de don Benito Pérez Galdós, Madrid, 1941, tomo III, p. 574.

10 Ramón Mesonero Romanos, Memorias de un setentón, Madrid, 1961, tomo II, pp. 204-206. 


\section{ALCALÁ GALIANO Y LOS CURSOS DE DERECHO CONSTITUCIONAL DEL ATENEO}

Alcalá Galiano ocupó la cátedra de Derecho Constitucional del Ateneo de Madrid en cuatro ocasiones y lo hizo con una cierta discontinuidad que no deja de tener interés para la semblanza que estamos trazando. Como vimos en su momento, el Ateneo de Madrid celebró su sesión constitutiva el 26 de noviembre de 1835 y su inauguración solemne tuvo lugar el 6 de diciembre de ese mismo año. Lo hizo con notorias dificultades de locales y, pese a ello, con una decidida preocupación por abrir sus cátedras cuanto antes adscribiéndolas desde un principio a muy relevantes personalidades de la vida pública española del momento. El acta de la Junta General de 28 de abril de $1836^{11}$ nos da cuenta de ello y, al hilo de tales consideraciones, incluye además la primera noticia de la cátedra de Derecho Político Constitucional así como de la aceptación de don Antonio Alcalá Galiano para ocuparla: «Abierta (la sesión) por el señor Consiliario Olózaga, a falta del Presidente, y aprobada el acta anterior - se lee allí-, di cuenta de las aceptaciones de don Antonio Alcalá Galiano para explicar la cátedra de Política Constitucional...», mención que se prolonga con la de otros profesores y otras disciplinas.

Desde un primer momento, pues, se pensó en Alcalá Galiano como titular de dicha cátedra, no obstante lo cual esa docencia no se produjo entonces en parte porque, como la referida acta de 28 de abril de 1836 nos informa, en esa misma sesión y en razón de la penuria de locales que por entonces el Ateneo padecía, «se determinó suspender la apertura de las Cátedras hasta tener mejor localidad» ${ }^{12}$, pero en parte también y sobre todo porque determinados acontecimientos políticos la hicieron imposible.

Y no se trata de que el 15 de mayo de dicho año, dieciséis días después de aquella suspensión, don Antonio Alcalá Galiano fuera nombrado Ministro de Marina del recién designado Gobierno Istúriz, lo que ya podría haber sido motivo suficiente para que el profesor aplazara el cumplimiento del encargo que el Ateneo le había hecho, sino de otras circunstancias muy distintas. De hecho, el 18 de junio de 1836, cuando - contra todas las previsiones - el Ateneo había podido dar una solución provisional a su mencionado problema de locales ${ }^{13}$, Mariano José de Larra exhortó a Alcalá Galiano desde las páginas de «El Español» en términos muy perentorios a compatibilizar ambas ocupaciones, la de profesor y la de Ministro: «...en cuanto a establecer dudas acerca de la incompatibilidad de la silla

11 Vid. el acta de dicha sesión en el Libro primero de Actas del Ateneo, 1836-1841.

12 El acta citada da cuenta de cómo el Secretario de la institución, Ramón Mesonero Romanos, puso a la consideración del Ateneo si se tomaría la habitación baja para abrir las cátedras, aunque fueran pequeñas, y cómo, después de intervenir varios socios, se decidió aplazar su apertura.

13 La solución consistió en el traslado al n. ${ }^{\circ} 27$ de la calle del Prado, distinto del que finalmente iba a ser el local definitivo del Ateneo, todavía exiguo pero suficiente para comenzar con un mínimo de holgura su actividad. 
ministerial y de una silla de catedrático — escribió allí - es demasiado ilustrado el señor Galiano, y sonlo también bastante nuestros lectores para vivir persuadidos de que, no sólo no existe incompatibilidad ninguna, sino que semejante coincidencia sólo podría resultar en bonor y gloria del ministro que pudiese realizarla. (...) Las lecciones de un ministro catedrático son algo más populares, más francas, menos engañosas, que los apretones de mano que puede dar un rey ciudadano a sus compatriotas» ${ }^{14}$. Y sea por tales instigaciones o sea porque Alcalá Galiano así lo tuviera decidido, lo cierto es que el acta de la Junta General del Ateneo de 29 de junio de 1836 nos da cuenta de la comunicación de Galiano declarándose dispuesto a comenzar sus explicaciones, con lo cual queda claro que no fue su designación como Ministro lo que impidió que éstas tuvieran lugar: "... se dio cuenta — dice el acta- de un oficio del señor don Antonio Alcalá Galiano en que manifestaba que hallándose pronto a desempeñar la cátedra de Derecho Público se le señalasen los días en que podría verificarlo, habiendo becho presente el Secretario de palabra haber oficiado a dicho señor manifestándole los días en que no había otras enseñanzas» ${ }^{15}$.

Fueron, pues, otras y más graves las causas que entonces lo apartaron de la cátedra. En concreto, fue el creciente estado de agitación del país que por aquellos días se produjo el que, entre los días 12 y 15 de agosto, desembocó en la sublevación progresista de los sargentos de La Granja, el forzado restablecimiento de la Constitución de Cádiz y la caída del Gobierno Istúriz, del que Alcalá Galiano formaba parte como Ministro, lo que, según los malos hábitos del momento, supuso una vez más la persecución política de los derrotados y la necesidad de que éstos se refugiaran en otro país. Alcalá Galiano —emigrado una vez más— pasó a Francia no sin complicadas peripecias de las que él mismo nos informa en sus páginas autobiográficas ${ }^{16}$. Y allí hubo de permanecer durante casi catorce meses, lo cual hizo que cuando se abriera la cátedra el 22 de noviembre de 1836 ésta no pudiese ocuparla su primer titular, Alcalá Galiano, sino un jovencísimo Donoso Cortés capaz de llenar con exceso las exigencias moderadas (en Donoso no hay

14 Mariano José de Larra, «El Español», 18 de junio de 1836. Allí, Larra le recuerda además a Alcalá Galiano que tal situación no es nueva y que en otras ocasiones, en las que la misma ha afectado a personalidades no menos eminentes que la suya, ello no ha impedido dicha compatibilidad: "Y ejemplos de éstos hemos visto en países extranjeros —escribe Larra-. Sin ir más lejos M. Guizot ha sabido ser, al mismo tiempo, ministro y profesor de Historia Moderna en el Colegio de Francia, M. Cousin y M. Villemain, catedráticos a la vez que pares, han sabido llevar de frente la enseñanza pública en una cátedra y la discusión en la tribuna de los grandes intereses de la patria...».

15 Libro primero de Actas del Ateneo, 1836-1841, cit.

16 Antonio Alcalá Galiano, Apuntes para la biografía del Excelentísimo Señor Don Antonio Alcalá Galiano escritos por él mismo, incluido en la Biblioteca de Autores Españoles Obras escogidas de D. Antonio Alcalá Galiano, Madrid, 1955; vol. II, pp. 297-298: «... hube de esconderme — dice allí-para evitar la muerte que me amenazaba y que había caído sobre el dignísimo e infeliz Quesada. Istúriz y yo fuimos los únicos ministros que estuvieron en el real palacio en la mañana del 15 de agosto (...).». Tras esconderse en Madrid en casa de Don Manuel Montes de Oca y en otros domicilios, pudo salir por fin para Francia el 6 de septiembre pasando a pie por la Puerta de Bilbao y siguiendo en una silla de postas que le esperaba cerca de la plaza de toros. «No sin correr grande peligro — concluye-, pude verme en Francia, pues en Zaragoza, por donde pasé de día, habría sido muerto si bubiese sido conocido». 
contradicción al conjugar moderación con exceso) que tan bien le conocemos al Ateneo de Madrid de aquella época ${ }^{17}$.

Regresado de la emigración, hacia diciembre de 1837 el Ateneo volvió a ofrecerle a Alcalá Galiano la cátedra de Derecho Político Constitucional. El acta de la Junta General de 10 de febrero de 1838 da cuenta de su aceptación para el ya bastante avanzado curso 1837-38 y, según los sucesivos anuncios aparecidos en "El Correo Nacional» ${ }^{18}$, el profesor comenzó sus explicaciones el 6 de marzo del último de tales años no pudiendo extenderlas más allá del 15 de junio (catorce lecciones pudo impartir en total) pues para esta fecha, como era lógico dada la llegada del verano, el Ateneo cesó toda actividad docente.

Los dos cursos siguientes, 1838-39 y 1839-40, Alcalá Galiano volvió a ocuparse de la asignatura. No sucedió así en los tres cursos inmediatos 1840-41, 1841-42 y 1842-43 (cursos en los que, por cierto, el Ateneo de Madrid prefirió suprimir la cátedra antes que encomendarla a un progresista, según consta en sus $\operatorname{actas}^{19}$ ) porque de nuevo las circunstancias políticas volvieron a vedarlo. Con el pronunciamiento progresista de 1 de septiembre de 1840 dieron comienzo tres años de predominio esparterista que obligaron a los políticos moderados a ausentarse una vez más de la política española. Alcalá Galiano hubo de ocultarse primero en las provincias vascongadas para pasar finalmente a Francia, de donde no regresó hasta septiembre de 1843 . A su regreso, el Ateneo le encomendó de nuevo la cátedra de Derecho Político Constitucional que ocupó por cuarta y última vez durante este curso de 1843-44. Al ocupar la tribuna en esta postrer ocasión, el profesor no pudo dejar de rememorar las circunstancias que lo habían tenido separado de dicha docencia. «Sin embargo — diría no sin alguna inexactitud relativa a la presunta neutralidad del Ateneo-_... este instituto, a pesar de su deseo de aparecer y de mantenerse neutral, no ba podido menos que resentirse de los tiempos revueltos en que se ba encontrado; (...) Hombres de todas las opiniones se presentan en este recin-

17 El propio Donoso Cortés se consideraba un sustituto: «Si el ilustre publicista que debía desempeñar esta cátedra estuviese entre nosotros, — diría al iniciar sus explicaciones - yo vendría como discípulo a recibir las inspiraciones de su genio y las lecciones de su elocuencia, pero ya que esto no es posible permítaseme a lo menos rendirle aquí el homenaje que es siempre debido a la superioridad del talento y a la santidad del infortunio». Vid. JuAn Donoso CoRTÉs, Lecciones de Derecho Político, edición del Centro de Estudio Constitucionales, Madrid, 1984, p. 5.

18 «El Correo Nacional», vid. los números correspondientes a los días 5, 12, 19 y 26 de marzo, así como 2, 9, 16, 23 y 30 de abril, 1, 15, 22 y 29 de mayo y 5 de junio de 1838. En tales anuncios se da noticia de los días y horas en los que Galiano iba a impartir la asignatura

19 En efecto, don Fernando Corradi, progresista vinculado a la redacción de El Eco del Comercio y ateneísta que ya había regentado en este establecimiento la cátedra de Literatura extranjera, solicitó formalmente ocupar la cátedra que dejaba vacante Alcalá Galiano tras su salida hacia Francia. Dicha solicitud la apoyaron cincuenta y ocho socios, los cuales depositaron una proposición en la que se leía: «Habiendo negado la Junta gubernativa del Ateneo la apertura de la cátedra de Derecho público constitucional, sin duda para ebitar (sic) cuestiones políticas... pedimos: Que se permita la enseñanza... para no incurrir en ... menoscabo de la imparcialidad que debe distinguir siempre a este establecimiento». No obstante, según nos sigue informando la misma Acta en la que se da cuenta de tal proposición, sometida ésta al voto de la Junta y tras una discusión bastante acalorada, dicha propuesta fue rechaza por 42 votos favorables al mantenimiento de la supresión de la cátedra frente a sólo 29 partidarios de su restablecimiento. Vid. Acta de 19 de diciembre de 1840, Libro primero de Actas..., citado. 
to, de que se vieron apartados algunos, entre los cuales se cuenta mi bumilde persona, y el Ateneo ve volver a su seno a todos los individuos que adoptó (...). Imposible es, señores, bablar de este asunto sin conmoverse; para mantenerse insensible abora sería necesario ser superior a la naturaleza humana, o bien inferior hasta llegar a volverse como piedra... ${ }^{20}$.

Galiano, en fin, puso el mayor empeño y cuidado en sus explicaciones de aquel curso $^{21}$ tomadas taquigráficamente por don Antonio Ferrer del Río y don Juan Pérez Calvo, y fue sobre su texto sobre el que finalmente acabó por imprimirse la obra completa tras de salir adelantadas a la calle las distintas lecciones en forma de cuadernillos ${ }^{22}$. La edición de la misma corrió a cargo de D. Ignacio Boix, cuyo establecimiento estaba sito en la calle de Carretas número 8, y la obra va dedicada por el autor a sus electores de la provincia de Barcelona, llevando pie de imprenta de $1843^{23}$. En la última de las lecciones Alcalá Galiano incluyó una emocionada despedida de la cátedra que era todo un aviso de que no se seguiría ocupando de dicha materia en los cursos posteriores: «Duéleme, señores, — diríaanunciar que es casi seguro que será esta la vez postrera que ocupe esta cátedra (...) lo bago porque creo mi vida política terminada (...). Ningún lugar estimo más a propósito para mi despedida del mundo político que el presente. Lo digo con sinceridad, y no sin sentirme vivamente conmovido, señores; si en más importante y afamado teatro alguna vez be tenido entre momentos amargos otros dulces, de estos últimos, si acaso igualan, por cierto ninguno excede a los que be pasado en el Ateneo» ${ }^{24}$.

Alcalá Galiano volvió a ocupar, no obstante, alguna otra cátedra (la de Historia de la literatura española, francesa, inglesa e italiana en el siglo XVIII, para el curso 1844-45), pero no la de Derecho Político Constitucional que pasaría a regentar don Joaquín Francisco Pacheco.

20 Antonio Alcalá Galiano, Lecciones..., cit., pp. 470-473. En estas páginas, Alcalá Galiano alega que considera concluida su vida política como causa de su abandono de la asignatura. En realidad, era más cierto que para entonces había aceptado ocuparse de la dirección del colegio de San Felipe Neri, en Cádiz, empleo que en otro tiempo había regentado don Alberto Lista, y que tal ocupación hacía difícil su compatibilidad con la cátedra del Ateneo. No obstante, antes de ocupar dicho empleo en Cádiz el Gobierno le ofreció el puesto de Comisario Regio del Banco de España, razón por la cual nunca abandonó Madrid y sí ocupó una cátedra distinta en el Ateneo para el curso siguiente. De todo ello da cuenta Alcalá Galiano en Apuntes para la biografía..., op. cit., p. 303.

21 El Ateneo quiso hacer un reconocimiento explícito de la calidad de las explicaciones de Alcalá Galiano durante aquel curso dejando constancia de ello en el acta de 31 de mayo de 1844, cuyo texto dice: «Habiendo concluido sus Lecciones de Derecho Político Constitucional el señor don Antonio Alcalá Galiano, a propuesta del infrascrito secretario se acordó dar a aquel ilustrado catedrático un voto de gracias por el celo y lucimiento con que se había dignado explicar dicha asignatura en el presente año». Vid Libro segundo de Actas del Ateneo, acta de la fecha.

22 El Eco del Comercio, n. ${ }^{\circ} 479$, de 16 de enero de 1844, incluye el siguiente anuncio referido a las Lecciones de Alcalá Galiano: «Esta obra se publica por entregas de 64 páginas en 8. prolongado o sean cuatro pliegos de impresión, a 5 reales y 6 en provincias franco el porte. La primera entrega está ya corriente y de venta en la librería de su editor don Ignacio Boix, calle de Carretas, $n .^{\circ} 8$ ".

23 Antonio Alcalá Galiano, Lecciones de Derecho Político Constitucional, Imprenta de D. I. Boix, Madrid, 1843. El Centro de Estudios Constitucionales ha reeditado el texto en la colección Clásicos del constitucionalismo español, con un estudio preliminar del autor de esta semblanza, Madrid, 1984.

24 Antonio Alcalá Galiano, Lecciones..., despedida cit. 


\section{SOBRE LA PERSONALIDAD DE DON ANTONIO ALCALÁ GALIANO, PROFESOR DE DERECHO CONSTITUCIONAL. SUS RASGOS FUNDAMENTALES}

Cuando dijimos al inicio de esta semblanza que Don Antonio Alcalá Galiano, a diferencia de los otros profesores de la disciplina de cuya trayectoria intenta dar cuenta Teoría y Realidad, no era en absoluto un profesor universitario decíamos todavía únicamente media verdad. Más allá de ello, Alcalá Galiano no solo no ejerció jamás como profesor universitario en ninguna de las Facultades de Jurisprudencia de este país sino que, para mayor extrañeza, ni siquiera fue un jurista. Él, que iba a realizar la más cumplida síntesis de nuestra disciplina en aquel momento de la cultura española, nunca llevó a cabo estudios de Derecho ni tuvo título alguno que le acreditara formalmente como poseedor de tales pericias. Su trayectoria como profesor de Derecho Constitucional, inconcebible hoy sin duda, fue muy distinta. Fue la de un hombre público cuya formación procedía de la política práctica unida a su condición de interesado lector de la mejor literatura constitucional de la época y a la experiencia que le proporcionó la emigración con sus dilatadas estancias en Francia y en Inglaterra. Es este bagaje, y no una estricta dedicación jurídica o universitaria, la que le hizo aceptar un día el encargo de ordenar todos estos materiales y comunicarlos a las élites de su tiempo desde esa singular tribuna que fueron las cátedras del Ateneo de Madrid. De ahí que debamos dedicar aquí algún espacio a describir su inusual personalidad. Lo haremos por referencia a los que bien podrían ser los cuatro rasgos más definitorios de la misma.

1. Profesionalmente, Alcalá Galiano, de quien acabamos de recordar que no fue un jurista, bien pudo haber sido un militar, oficial de Marina como su padre; hijo de don Dionisio Alcalá Galiano, el héroe muerto en la batalla de Trafalgar (1805) estando al mando del Bahama, recibió en 1801 merced a los méritos de su padre - una oferta del Ministro Godoy que le hubiera permitido dejar su puesto de cadete en los Guardias Reales y pasar a prestar servicio en la Marina española como alférez de fragata, pero su padre declinó tal ofrecimiento y con ello truncó dicho camino, lo que no impidió, sin embargo, que el joven Alcalá Galiano conservara desde entonces lo que él mismo llamaría "una afición loca a la mar» y aun que, andando los años, llegara a ser Ministro de Marina. En 1806 optó por seguir la carrera diplomática en la que llegó a tener nombramiento como Secretario de Legación, primero en la Legación de España en Suecia y más tarde en la de Brasil, no obstante lo cual no llegó a ejercer ninguno de ambos empleos, en el primer caso porque retuvo el citado nombramiento durante cuatro años (1814-1818) sin acabar siquiera de ocuparlo, 
con lo cual el Gobierno designó para dicho destino a otra persona ${ }^{25}$, y en el segundo caso porque cuando iba a embarcarse hacia Brasil en 1819 prefirió quedarse en España participando en las conjuras ya iniciadas contra Fernando VII, rey absoluto.

$\mathrm{Y}$ es que, en realidad, sus medios de subsistencia provinieron siempre de una doble fuente mucho más acorde con sus inclinaciones y con su personalidad: por una parte, de su actividad como hombre público destinado por su formación a empleos o cometidos distintos (desde el de diputado por diversas provincias españolas, cunero en alguna de ellas, hasta el de Ministro en más de una ocasión) y, por otra parte, de su calidad —más o menos afortunada, eso lo veremos después - como rentista propietario de un determinado haber (mayorazgo de su familia en Cabra; fortuna no menguada hecha por su padre en sus expediciones a América gracias a su sueldo y a las entonces llamadas pacotillas — «en 1801 regresó mi padre bastante rico»-; negocios en Cuba, etc... $)^{26}$.

2. Vocacionalmente, Galiano fue, a su vez, un tribuno, esto es, un ser particularmente dotado para el uso apasionado y persuasivo de la palabra, arte en el que llegó a ser un verdadero virtuoso. Leopoldo Alas «Clarín», que por su edad no llegó a conocerle, cuenta que cuando el Ateneo le encargó una conferencia sobre Alcalá Galiano para incluirla en un ciclo sobre la España del siglo XIX, se dirigió a las personas que sí lo habían conocido y, entre ellas, a don Emilio Castelar, tal vez el mejor orador de su tiempo, el cual le contó que en sus años jóvenes, siendo modestísimo estudiante, solía ir a escuchar a Galiano, del que guardaba el siguiente recuerdo: «Yo babía oído (...) a los más ilustres oradores — le refirió Castelar_-, sabía ya lo que era la oratoria, y de todo aquello me sentía yo capaz; pero al oír a Alcalá Galiano (...) al contemplar aquella obra admirable en que nadie podía darse cuenta de los andamios (...), al admirar aquella ardiente inspiración, verdaderamente me sentí deslumbrado, y me senti temblar como tiembla el hombre de vocación cuando se encuentra frente a frente con el maestro». Tal vez por eso (jugando a la vez con el hecho de la fealdad de Galiano $^{27}$ y con el recuerdo de la anécdota que cuenta que Esquino, vencido por la oratoria de Demóstenes, decía a los alumnos que alababan la suya: « $A b_{j} ; P$ ies si bubieseis oído al

25 «Entonces se dio a otro mi destino de secretario de la Legación de España en Suecia, que yo conservaba a los cuatro años de no estarle desempeñando», en «Apuntes...», p. 287.

26 Para todos estos datos, Apuntes..., p. 283 y ss.

27 La fealdad de Alcalá Galiano fue siempre objeto de múltiples chanzas. Vid., por ejemplo, MANUEL Del Palacio y Luis de Rivera, Cabezas y calabazas, Retratos al vuelo de las notabilidades de la política... pintados al fresco por Manuel del Palacio y Luis de Rivera, Madrid, 1864, donde se dedican a Alcalá Galiano los versos siguientes: "¿No dicen que la elocuencia / embellece mucho al hombre? / Pues por su cara, Galiano / tiene poco de Demóstenes». 
monstruo...j») Leopoldo Alas decidió comenzar aquella conferencia diciendo «Señores, yo no be conocido al monstruo» ${ }^{28}$.

Esa capacidad la puso Alcalá Galiano, desde luego, al principio de su vida pública y particularmente durante el Trienio, al servicio de la más avanzada defensa de las ideas liberales. Por eso la imagen que se recuerda de él es, sobre todo, la del fogoso orador de La Fontana de Oro, perfil que, en no pequeña medida, ha contribuido a idealizar Pérez Galdós ${ }^{29}$ en sus Episodios nacionales ( «...en su mirada profunda (había) la penetración y el juego de los ingenios de la antigua raza») y a la que también colaboró Leopoldo Alas en la conferencia antes citada ( Alcalá Galiano — diría allí— representa el buracán de la revolución introducido como un torbellino en un cerebro»).

Cabría pensar, no obstante, que esa capacidad oratoria suya cedió con los años y que ya no formaba parte de sus destrezas cuando Galiano, venido con el paso del tiempo a posiciones infinitamente más moderadas, ocupó la cátedra de Derecho Constitucional del Ateneo. Sin embargo nada es menos cierto. Esa fluidez convincente es, si cabe, una de las claves fundamentales que hicieron a la brillantez de dicho curso, el cual difícilmente se entendería sin ella. Bastaría a demostrarlo el testimonio de una de las más insignes personalidades que asistieron a tales lecciones, el escritor y viajero francés Edgar Quinet, ya mencionado al hablar del Ateneo, quien dedicó uno de los capítulos de su libro «Mis vacaciones en España» a dejar constancia de ello: "Yo be escuchado — escribió en el capítulo titulado «Un profesor»—algunas lecciones del exministro señor Alcalá Galiano, que pasa, y con razón, por ser uno de los oradores más eminentes de España. No se puede uno figurar lo que es la lengua española en boca de hombre semejante. Me parece reunir a la vez la melodía del italiano, la aspereza del árabe, el vigor del sajón, la gracia del provenzal... Dicen que sólo él ha conservado el secreto de esta elocuencia de grandes giros asiáticos (...) iQué lástima —añadiría Edgar Quinet, tras advertir un cierto dejo de cansancio en las palabras del orador, secuela de lo mucho visto y vivido, sin que ello rebajara no obstante su admiraciónque el desaliento apunte bajo estos esplendores de lenguaje; (...) ¿Qué debió ser en los tiempos en que creía en el porvenir?» ${ }^{30}$.

3. Ideológicamente fue, por lo que respecta a tal aspecto, un liberal exaltado venido durante los años de las Lecciones a la moderación. En efecto, andando el tiempo y pasada su juventud, el fogoso orador de la Fontana de Oro acabó trasladándose a posiciones mucho más sosegadas, llegando a ser incluso uno de los principales puntales del Partido Moderado. El propio Galiano nos ha dejado, en sus abundantes páginas autobiográficas, más de

28 LeOpoldo Alas, «Alcalá Galiano. El periodo constitucional de 1820 a 1823», vigésimocuarta conferencia del ciclo La España del siglo XIX, Madrid, 1886, tomo II, p. 477.

29 Benito Pérez Galdós, La Fontana de Oro, Espasa Calpe, 1951, p. 25.

30 Edgar Quinet, Mis vacaciones en España, Madrid, 1931, pp. 61-62. 
un testimonio de dicha evolución. "Necio sí fui —escribe en sus «Memorias»- pues no queriendo ciertos fines, recomendé y aun abracé los medios que a ellos forzosamente llevan... ${ }^{31}$. Más aún, buena parte de tales páginas parecen ser un intento de rebajar su conocida imagen de revolucionario. Así, su recuerdo del disgusto que le causara en 1808 la mala traza de los guerrilleros callejeros y su sospecha, ya entonces, de que "debia temerlos tanto como a los franceses ${ }^{32}$ o su apelación a la náusea que le produjera en su día la imagen de Riego cantando el Trágala desde el palco del teatro del Príncipe $^{33}$, todo lo cual no logra convertir en verdad, sin embargo, el alegato que hace a favor de su moderación en "Apuntes para la biografía...», donde llega a decir que "es error creer que siempre fuese yo de los extremados» ${ }^{34}$.

Sea ello verdad o no, lo que sí es cierto - y a nosotros nos interesa- es que esa evolución nos sirve para definir el tipo de moderación que Galiano profesaba en el tiempo en que ocupó su cátedra. Baste pensar tan sólo que cuando el gusto por el justo medio establecido como moda entre la intelectualidad española era ya — si se nos permite decirlo de este modoel propio de la mentalidad francesa y doctrinaria, distanciada de la primera matriz liberal, los orígenes del liberalismo de Galiano le preservaron de ese riesgo dando a su moderación un sentido mucho más anglosajón y práctico, más fresco y conectado, si se quiere, a la que fuera su primitiva conexión con aquella ideología liberal. En otro lugar he escrito que, en mi sentir, hay en ello una clara razón generacional: Galiano, cualquiera que sea el tiempo transcurrido desde Cádiz y desde el Trienio y sin dejar de compartir con los doctrinarios múltiples conexiones y coincidencias, es un liberal de primera generación; los doctrinarios, en cambio, son la segunda generación de aquella ideología. ¿Dónde está la diferencia? Pues la diferencia está en que mientras Galiano «viene» del fervor liberal y puede permitirse el lujo de moderarlo, los jóvenes doctrinarios con los que Galiano convive «parten» ya sin embargo — con todo engreimiento ideológico- de éste que para él es su punto de llegada, razón que les impide incluir entre sus registros cierta sensibilidad. Diríamos que su pasión ya no es tanto la libertad cuanto la sensatez y el equilibrio, lo cual es otra $\cos ^{35}$.

31 Antonio Alcalá Galiano, Memorias, op. cit., vol. II, p. 81.

32 Antonio Alcalá Galiano, Memorias... Vid. lo que dice al respecto José María Jover, Conciencia obrera y conciencia burguesa en la España contemporánea, Madrid, 1959, p. 15.

33 Historia de España... redactada y anotada con arreglo a la que escribió Dumbam, por ANTONIO ALCALA GALIANO, tomo VII, p. 114.

34 Antonio Alcalá Galiano, Apuntes..., op. cit., p. 286.

35 Ángel Garrorena, Antonio Alcalá Galiano y el Derecho Constitucional en la primera mitad del siglo XIX, estudio preliminar a la reedición de las Lecciones... hecha por el Centro de Estudios Constitucionales, Madrid, 1984, pp. XLIV-XLV. 
En todo caso, eso sí, la razón fundamental del compromiso de Alcalá Galiano con la ideología moderada hay que buscarla — cambiando de registro- en sus raíces burguesas, de las que ya tenemos alguna noticia. Es esa condición suya de miembro de una clase social poseedora (propietario de bienes, mayorazgo, negocios en Cuba...) la que termina influyendo en su carácter y provocando en él una forma de pensar, aunque esas propiedades — como en el caso de Galiano_ no fueran muchas ni muy rentables ( «mis negocios de la Habana no iban bien ${ }^{36}$, dice en una ocasión). De hecho, cuando el 11 de abril de 1865, siendo Ministro, se desploma muerto sobre la propia mesa del Consejo de Ministros, sus compañeros de Gabinete tuvieron que sufragar su entierro ${ }^{37}$, extraño final para quien desde la política y desde la cátedra había defendido con la mayor convicción las excelencias de la propiedad.

4. Pero, más allá de todo lo anterior, el Alcalá Galiano que imparte Derecho Constitucional en el Ateneo de Madrid fue un erudito con una preparación nada común en la España de su tiempo. Contribuyeron a dicha formación sus prolongados años de exilio tanto en Inglaterra como en Francia (dato éste que sí compartió con otros compatriotas merced al hecho frecuente de la emigración), su fluido dominio de las lenguas inglesa y francesa y su permanente atención a la práctica política y a la producción científica y literaria de ambos países.

Su contacto con Francia fue, con todo, algo menor ya que cuando su condición de emigrado le forzaba a realizar estancias más largas fuera de España, de Francia pasaba enseguida a Inglaterra y de Inglaterra volvía a Francia tan sólo cuando la situación política española la aconsejaba acercarse más a nuestro país. No obstante, ese contacto existió y fue bastante intenso. Recordemos que desde muy joven, antes incluso de que en España se abriera la etapa constitucional, su interés por los autores franceses fue, como él mismo nos dice, muy claro; de hecho, en sus Memorias nos cuenta que en la biblioteca de sus tíos Vicente Alcalá Galiano y Rafael de Villavicencio ciertos libros encuadernados como comedias de Calderón contenían las obras —entonces prohibidas- de Montesquieu, Voltaire o Rousseau, a las que él intentó acceder con toda la frecuencia que le fue posible ${ }^{38}$. Durante el tiempo de Cádiz, copió, por ejemplo, los argumentos de Mirabeau para defender el veto real ${ }^{39}$. Y ya mayor, en su etapa de emigrado, sobre todo entre 1830 y 1834 , estuvo en relación con la clase política francesa próxima a sus ideas, estableció contactos con el general Lafayette y con otras personalidades francesas del momento - Benjamín Constant entre ellas, como veremos des-

36 Antonio Alcalá Galiano, Apuntes..., op. cit., p. 287.

37 Vid. El Contemporáneo del día siguiente, 12 de abril, n. ${ }^{\circ} 12$.

38 Antonio Alcalá Galiano, Memorias..., ed. cit., vol. I, pp. 276-277.

39 Antonio Alcalá Galiano, Recuerdos de un anciano, ed. cit., p. 81, nota 10. 
pués-, mantuvo alguna relación personal con Remusat, de la que nos da cuenta Margaret A. Williams ${ }^{40}$, hacia 1830 pasó a recibir una subvención del Gobierno francés de la que pudo vivir durante año y medio, colaboró en la Revue Trimestrielle, y si bien no sería correcto decir que vivió la vida de aquellos años como un francés más, sí es verdad que los asumió como un español muy interesado por los sucesos de Francia ${ }^{41}$.

Por lo que hace a sus lecturas, Galiano confiesa que se dejó llevar siempre más por las inclinaciones de su espíritu que por los prestigios acuñados o por las modas doctrinales.

Eso explica que, como ha advertido muy bien Díez del Corral ${ }^{42}$, la repercusión directa de los doctrinarios franceses sobre Alcalá Galiano sea menor. No cabe duda de que Galiano, que pasó precisamente desde Inglaterra a Francia al principio de la revolución de julio y del régimen orleanista y allí vivió la puesta en marcha del que se puede considerar el principal experimento doctrinario de Francia, conocía muy bien la personalidad y la obra de Royer-Collard, de Guizot o de Broglie, pero estos nombres apenas tienen un reflejo directo en sus escritos y desde luego solo lo tienen lateral y esporádico en las Lecciones del Ateneo. Otros influjos — la huella de lo inglés — y otras preferencias — su memoria de primer liberal- lo impidieron. Se diría que Galiano es más doctrinario en sus consecuencias que en sus fuentes directas y en sus afectos.

Esa puede ser también la explicación de que su lectura de Montesquieu, que sin duda hizo en directo, aparezca sin embargo en sus Lecciones interferida por la de un autor de segunda fila como es Destutt de Tracy en su Commentaire sur l'Esprit des Lois de Montesquieu, publicado con destino a Estados Unidos y después reimpreso en Paris en 1819. Sobre Destutt de Tracy dice Galiano en su lección primera: «...nunca ba sido reputado trabajo de primer orden. Y al elogiarle en algunas cosas, señores, diré que en mi entender las tiene buenas en alto grado». Y es que Destutt de Tracy es para él el pensador sensualista con cuya idea de «felicidad», en cierto modo próxima al concepto benthamista de «utilidad», acaba encontrando esa mayor identificación personal que busca al seleccionar sus fuentes.

Aparte lo anterior, la principal lectura francesa del Galiano profesor de Derecho Constitucional del Ateneo lo fue el Curso de Politica Constitucional de Benjamín Constant, también un liberal de primera generación venido después a la moderación, como él, y por lo tanto un espíritu con quien Galiano puede entenderse. Del Curso de Constant dice Alcalá Galiano en sus Memorias: «...habia llegado a mis manos el Curso de Política Constitucional de Benjamín Constant en su original francés y no sólo le habia leído yo con gusto, sino que le había tomado por símbolo

40 Margaret A. Williams, «Some State documents concerning Alcalá Galiano’s exile in France», en Hispanic Review, vol. XXIX, 1961, n. ${ }^{\circ}$ 2, págs, 116.

41 Sobre la etapa de su exilio en Francia durante los primeros años del reinado de Luis Felipe de Orleans, hay bastantes datos en Apuntes..., op, cit., pp. 294 a 296.

42 Luis Díez Del Corral, El liberalismo doctrinario, 2. ${ }^{a}$ ed., Madrid, 1956, p. 476. 
de mi fe política, teniendo por bueno y óptimo cuanto allí se sienta y recomienda en todas sus partes» ${ }^{43}$. Sin embargo, esa admiración por Constant descendió algo a raíz de una desafortunada entrevista habida hacia 1830 en la que el profesor y político español, tras pedirle a Constant apoyo para la causa española, tuvo que escuchar una respuesta poco pertinente a la que él acabó contestando de idéntica manera. «Pocas y cortas frases siguieron a éstas, —escribe Galiano-y me despedí, siendo probable baberle yo disgustado tanto cuanto él a mí, si no más todavía... ${ }^{44}$.

Y no sería correcto cerrar este recorrido sin recordar que Alcalá Galiano conoció y utilizó asimismo en sus Lecciones la obra de Alexis de Tocqueville sobre "La democracia en América», de la que la lección novena contiene un elogio nada común respecto de otros trabajos y otros autores: «...Mr. De Tocqueville — dice Galiano- en su obra inmortal sobre la democracia en América, escrito donde por la vez primera ba sido bien examinado el gobierno de la muchedumbre, no considerado en globo o conjunto, sino además de en el todo en sus partes (...), con maestría tal que acredita al autor de pintor de primera clase...».

No obstante, su inclinación — casi natural-y sus preferencias le vincularon siempre, en mucho mayor grado, a Inglaterra. «Por ser lo que llaman las gentes anglómano paso — reconoce en sus «Recuerdos de un anciano»-y no puedo negar que en algún grado lo soy, y desde los años primeros de mi edad adulta comencé a serlo, y en lo que eran vagas inclinaciones nacidas de circunstancias particulares me han confirmado después mis estudios» ${ }^{45}$. Y en otra ocasión, precisamente en referencia a Donoso Cortés, quien le había sustituido en la cátedra del Ateneo durante el curso 1836-1837, llegó a afirmar: "Porque siguiendo usted la escuela de los pensadores alemanes y de los franceses modernos discípulos de éstos, gusta de generalizar y en todos los casos de ascender a las abstracciones más elevadas (...), al paso que yo, pobre secuaz de los autores ingleses, que be manejado mucho, formándome en gran manera por ellos, me contraigo demasiado a las cuestiones especiales de que trato, y a eso agrego en mi estilo llano y pedestre una desconfianza suma de mis propios juicios, hallándome objeciones que ponerme, y declarándolas basta llegar al punto de incluir en un mismo período dos o más opiniones diversas y contradictorias» ${ }^{46}$.

Por lo que interesa a este trabajo, está claro, pues, que la integración del Alcalá Galiano emigrado con la Inglaterra que lo recibe (durante los siete años

43 Memorias..., op. cit., p. 81.

44 «No fue para mí de tanto agrado — cuenta Galiano en sus Recuerdos de un anciano- ni aún de alguno, la visita que bice al afamado Benjamín Constant. Había sido yo admirador apasionado de sus escritos (...) y aún hoy lo soy en bastante grado (...). Pero, aun con toda mi admiración de entonces, Sali de mi corta conversación con el famoso publicista por demás descontento. Porque habiendo yo manifestado a aquel célebre personaje que tratábamos de dar cuanto antes a nuestra patria la libertad (...), él (...) me dijo: Ab; il ne faut pas, que puede traducirse por no hay que hacer eso. Incomodado yo con gesto y tono que hubieron de ser desabridos, a qui ne faut-il pas?, le pregunté...». Vid. Recuerdos de un anciano, ed. cit., p. 230.

45 Antonio Alcalá Galiano, «Recuerdos de un anciano», en Obras escogidas, ed. cit.,vol. I, p. 232.

46 Antonio Alcalá Galiano, Breves reflexiones sobre la indole de la crisis por la que están pasando los gobiernos y pueblos de Europa, Madrid, 1848. 
que van de 1823 a 1830, amén de otros periodos menores) es total. Durante ese tiempo, Galiano es aceptado "como un amigo — dice- a quien se convida a la mesa" en los más destacados círculos sociales de Londres (Jorge Grey, sobrino del después primer ministro conde de Grey, Mr. Lamarchant, Mr. Griffin, el Aldeman Woor, miembro del Parlamento, entre otros... $)^{47}$, entra en contacto con ciertos ambientes intelectuales próximos a Bentham y escribe en la Westminster Review, órgano de los benthamistas radicales, también en la Foreing Quaterly Review o en el Times de Londres en el que llegan a aparecer cartas suyas ${ }^{48}$, asiste a los debates de la Cámara de los Comunes y copia y analiza sus discursos, se interesa por las prácticas políticas inglesas (los meetings, la disciplina de partido en las votaciones...) que intenta trasladar a España ${ }^{49}$, y cuando un grupo de personalidades funda en 1828 la University of London le ofrecen la cátedra de lengua y literatura española que él no duda en aceptar ${ }^{50}$.

Si de esta experiencia personal pasamos a analizar sus fuentes, es obvio que Galiano fue, asimismo, un gran lector de los autores ingleses. En sus Memorias recuerda haber manejado, hacia sus veinte años, a Milton, a Gibbon (sus lecciones reflejan la lectura de la History of the decline and fall of the Roman Empire), a Roberstson o a Hume, es decir, a lo mejor de sus poetas, sus historiadores o los representantes del empirismo inglés, corriente que se avenía muy bien con su temperamento analítico ${ }^{51}$. También fue un buen conocedor de la obra de Adam Smit The Wealth of Nations (tan útil para respaldar el sentido burgués de la creación de riqueza), de la que había un ejemplar en la biblioteca de su tío Vicente y sobre la que ya había hecho hacia 1810 determinados extractos ${ }^{52}$. Y desde luego conoció a fondo la literatura inglesa de los dos últimos siglos con particular atención a las piezas de la muy vigorosa oratoria parlamentaria inglesa. En las lecciones diecinueve y veinte de su curso sobre la Historia de la literatura del siglo XVIII, impartido en el Ateneo en 1844-45, se ocupa de Walpole, Windham, Chesterfield, Pitt, Fox, Burke, Sheridan, el conde de Chatham y tantos otros, probando tener un

47 Antonio Alcalá Galiano, Recuerdos..., p. 235

48 ViCente Llorens, Liberales y románticos. Una emigración española en Inglaterra (1823-1834), México, 1954, ha fijado la paternidad de los artículos de Galiano en la Westminster Review, en un excelente trabajo; vid pp. 42-43, 289 y 297.

49 Vid. Memorias, p. 101 para la intención de trasladar a las Sociedades patrióticas españolas un papel semejante al de los meetings ingleses, o p. 150 para «la necesidad de formar un partido, en el que fuese sacrificada a vece la opinión particular (...). Disonó esta propuesta, pareciendo cosa contraria a la honradez e imitación de las cosas inglesas (...); convínose en que los españoles debíamos (...) caminar a nuestro modo, votando cada cual según su conciencia; determinación en sus efectos casi equivalente a la de los soldados que se resistiesen a hacer fuego en descargas, prefiriendo disparar cada cual según viese o creyera que podía dañar a uno o muchos de sus contrarios».

50 En Apuntes..., p. 294, recuerda que su sueldo en aquella cátedra era de doscientas libras esterlinas, unos 20.000 reales de vellón. Gibbon.

51 Memorias, pp. 375-376. Aquí recuerda Galiano que él inició incluso una traducción de la obra de

52 Memorias, pp. 257 y 376. 
conocimiento nada común de todos ellos ${ }^{53}$. En las Reflections on the French Revolution de Burke encontró además Galiano una importante fuente de inspiración a la hora de censurar a los revolucionarios franceses, a los que, siguiendo al autor inglés, llama en sus lecciones «arquitectos de ruinas», e igualmente en lo que se refiere al repudio de Burke por las reglas abstractas (vid. en la lección sexta el rechazo de Galiano hacia los ideadores de fórmulas racionales de gobierno «que, no obligados a hacer uno para llevarle a efecto y ponerle en práctica, pueden discurrirle y labrarle a su gusto en el vasto campo de la fantasía...») o a la visión burkeana del tiempo histórico entendido como tensión entre el pasado y la necesidad de adecuarlo al presente, combinando así tradición y progreso ${ }^{54}$.

Pero sin duda la influencia mayor la recibió Alcalá Galiano de Jeremía Bentham y del benthamismo, doctrina que en el tiempo de las Lecciones se consideraba ya algo pasada pero por la que Galiano conservó siempre una preferencia especial. En Londres conoció a John Bowring, fundador de la Westminster Review, órgano de los radicales de Bentham en la que — como sabemos- Galianó colaboró con trabajo tan apreciados como su artículo «Spain», y del benthamismo recibió a lo largo de toda su vida el sentido de la utilidad — de los interesescomo móvil del sistema político, el valor de la expediency o conveniencia como criterio para juzgar la realidad (vid. lo que dice Galiano en su lección cuarta sobre la correlación utilidad en Bentham, expediency en Paley) y esa preferencia por atender a la técnica (técnicas parlamentarias, legislación, diseño de las segundas Cámaras...) como clave de toda su construcción política que es también esencial en la obra del autor inglés. Con razón dice Alcalá Galiano en su lección tercera: «Habiendo sido yo un tiempo discípulo, aunque bumilde, de la secta de los benthamistas (...), me he separado un tanto, pero ligeramente, de los dogmas absolutos de la misma escuela. Pero no soy en esto (bien lo seré en otras cosas) de aquellos conversos que, al pasar de una creencia a otra, se vuelven furiosos contra la fe que abandonaron; no, señores, en este punto conservo algo de mis opiniones antiguas».

\section{EL CONTENIDO DE LAS LECCIONES}

Espíritu de tribuno pero punto de llegada moderado, compromiso personal indudable - activo - con la convulsa realidad política española pero también largos años de emigración y, por lo tanto, de contacto con las experiencias constitucionales de Inglaterra y de Francia, ambas más avanzadas y distintas de la nuestra, lector constante de los doctrinarios franceses pero más admirador de la teoría política inglesa, de Burke a Bentham, con su mayor pragmatismo y

53 Antonio Alcalá Galiano, Historia de la literatura española, francesa, inglesa e italiana en el siglo XVIII, Madrid, 1845, p. 325 y ss.

54 Vid., por ejemplo, lo que Galiano dice en la lección segunda y en la lección final de su curso sobre tales cuestiones. 
con su mirada siempre pegada a los hechos, todo ello se trasladó al contenido de las Lecciones de Derecho Político Constitucional de Alcalá Galiano dando lugar a una enseñanza en la que (si se acierta a transcender, como se debe, su fuerte sobrecarga retórica, inevitable en aquel tiempo, pero más aún en Galiano de quien ya sabemos que se le consideraba «el monstruo», la palabra...) lo que encontramos —es verdad- es un curso con los claroscuros propios de la ideología política desde la cual su autor hablaba, pero también una obra con una capacidad singular a la hora de expresar con nitidez la imagen, el trasfondo social y los compromisos de la realidad constitucional de aquellos años, así como con una visión experta — especializada, por tanto- de ciertas cuestiones técnicas como no es posible hallarla entonces en nuestro país en ningún otro manual de la disciplina, ni en los escasos existentes en aquel momento ni en los publicados después hasta bien entrada la segunda mitad del siglo XIX. Sería correcto decir incluso que ambas virtudes son los principales «activos» de estas Lecciones de Derecho Constitucional.

En línea con lo dicho, el curso de Alcalá Galiano aportó una teoría de los regímenes políticos construida en razón de la estructura social que a cada uno de tales regímenes le subyace o, lo que es lo mismo, en virtud de su soporte de clase, lo cual supone una visión empírica, sociológica, bastante avanzada para su tiempo, si no en la práctica donde ya se sabía que las cosas eran así, sí al menos en el terreno de las construcciones teóricas llevables a la cátedra. Su idea es que todo régimen político, todo gobierno, siguiendo en este punto a Montesquieu, posee un «espíritu», un alma, y que es en la fidelidad de sus formas a ese espíritu en donde reside su coherencia y, por lo tanto, la clave de su estabilidad. Pero ¿cuál es ese «espíritu»? Pues para Alcalá Galiano no cabe duda. Ese «espíritu» (reconociendo aquí la calidad del análisis de Montesquieu, pero distanciándose ahora de su concreción $)^{55}$ lo pone la clase social predominante en cada caso, cuya mentalidad y cuya trama de intereses están llamadas a tintar y a dar sentido a todo el conjunto. Mantenerse fieles a ese «espíritu» es dar estabilidad a la vida política; romper la fidelidad con el mismo es, en cambio, desequilibrarlo todo. Por «espiritu —dice Galiano en sus Lecciones-entiendo en cuál clase están el influjo superior y el gobierno en varios estados respectivamente (...). Cuyo sea este poder, qué clase predomine haciendo preponderar su interés o dominar su influjo en un pueblo, es lo que en mi sentir constituye, y lo que aquí llamo el espíritu o alma de las constituciones ${ }^{56}$. Dicho de otra manera, es en la estructura social de un Estado y, dentro de ella, en las fuerzas

55 En el inicio de la lección segunda, compendio en cierto modo de la primera, dice Alcalá Galiano: «... no reconociendo yo las definiciones de Montesquieu de despotismo, monarquía y república, no puedo admitir el principio del mismo que declara el miedo como el alma del despotismo, el honor como el alma de la monarquía y la virtud como el alma de la república. Sin embargo (...), confesaré, señores, que en este principio que asienta, en esta causa que señala como espíritu motor de las diferentes clases de gobierno, si hay algo equivocado hay también mucho de cierto, mirando el mismo objeto por otra de sus faces». Alcalá Galiano, Lecciones..., p. 26.

56 Antonio Alcalá Galiano, Lecciones..., p. 42. 
reales de poder dominantes en esa sociedad donde reside su verdadera Constitución, lo que, dicho así, no está muy lejos de adelantar la idea de Constitución material que hoy manejamos.

En consecuencia, a partir de aquí Alcalá Galiano despliega unos desarrollos que acaban de dar cuerpo cabal a su teoría y, a su través, prácticamente a casi todo el curso. Para empezar, — nos dice- es verdad que la existencia de esa «clase predominante» resulta decisiva para la identificación del régimen político dentro del cual aquélla actúe. Pero en la realidad las cosas nunca son tan sencillas como eso, y como no lo son en la vida su mirada de buen observador empírico le avisa de que tampoco deben serlo en su construcción teórica. De hecho - concluyerara vez una clase social ha conseguido llevar su predominio hasta la anulación de las demás clases sociales y ni siquiera sería deseable que pudiera hacerlo. De ahí que junto a la idea de «clase social dominante» haya que utilizar, en su sentir, el concepto de «clases sociales moderadoras», entendiendo por tales aquellas que contrapesan, frenan y corrigen la dirección de la primera. A la postre, es en el punto y matiz de esa mixtura hábil, realista, entre clase dominante y clases moderadoras donde se halla el secreto de la viabilidad de un régimen. «En todos — afirma Galiano- debe preponderar un elemento hasta llegar a regir la sociedad y el estado. En todos debe estar templado con otros elementos el preponderante para impedir el exceso destructor de la fuerza extremada, y por este medio conservar a la sociedad o a la nación la vida» ${ }^{57}$. ¿Qué es, a fin de cuentas, lo que ha pasado aquí? Pues que Alcalá Galiano acaba de reformular la tradicional idea del régimen mixto en una correlativa y muy sugerente versión sociológica de la misma: la verdadera condición del régimen mixto reside, según su criterio, en una acertada combinación de todas las fuerzas que componen la estructura social del país de que se trate. Por eso concluye afirmando que «gobiernos mixtos puede baber, $y(. .$.$) en mi pobre opinión mixtos son casi todos», lo$ que en nada empece a la centralidad que a la clase predominante le deba corresponder.

Ello bien entendido, no tiene nada de extraño que buena parte de los temas de los que el curso después se ocupa fluyan desde tales premisas con toda naturalidad.

Tal es el caso de la teoría de la soberanía, construida por Galiano conforme a los patrones propios de la que cabría definir como la «soberanía de lo existente», bien que dicha fórmula nunca llagara a ser acuñada por el profesor dentro del curso de un modo explícito, lo que no impide que sí lo fuera - y con qué vigorde una manera implícita. «La soberanía que debe estar reconocida en las constituciones - afirma Galiano después de rechazar el dogma de la soberanía popular por considerarlo irreal en una sociedad en la que la mayoría de la población carece del derecho de sufragio - es la que está en ejercicio constante rigiendo con poder supremo el

57 Antonio Alcalá Galiano, Lecciones..., vid. la lección segunda y también, en parte, la lección tercera; para las citas que se hacen en el texto, vid. pp. 36 y 38. 
estado». Para ser más exactos, el poder constituyente reside en los poderes constituidos, los cuales gozan desde ya de la fuerza y el arraigo de lo que existe. Naturalmente, esos poderes, en nuestro país - y en todos aquellos otros Estados que cuentan con un monarca y unas cámaras representativas venidas del pasado- son las Cortes con el Rey, instituciones a las que en aquel momento se califica como «el origen de las cosas legítimas». "No señores — diría Alcalá Galiano, dejando, eso sí, la puerta abierta a otras formas de titularidad soberana bastante más discutibles, lo cual constituye la debilidad de su razonamiento — no debe bablarse de otra soberanía que la determinada e instituida por las leyes en cada estado; la que existe ya en los parlamentos con los reyes sobre ellos, y sin embargo obrando con ellos, donde hay parlamentos, y donde no los hay únicamente en región más encumbrada» ${ }^{58}$. Teoría en la que, si se advierte el compromiso del Monarca con las clases poseedoras y la identificación del Parlamentos con estas mismas clases sociales vía sufragio censitario, lo que le subyace - lo veremos después de un modo más claro- es una auténtica teoría de la soberanía de las clases medias, verdadero trasunto social de esa otra concepción formal de la soberanía de lo existente — de los poderes existentes - a la que nos acabamos de referir.

Algo semejante ocurre, asimismo, con su bien articulada construcción sobre la posibilidad de trasplantar las formas de gobierno de unos espacios a otros. Traslado éste que, en su criterio, no debería plantearse ni siquiera en el mero terreno especulativo sin antes comprobar si se dan las circunstancias que lo hacen coherente y, por lo tanto, posible; para decirlo utilizando sus propios esquemas, sin antes haber constatado si las condiciones sociales y la estructura de clases son o no las mismas en ambos Estados, esto es, en el que disfruta de la forma a trasplantar y en el que pretende importarla. No acertar a ver así las cosas — viene a sostener Galiano- es un error en el que se suele caer con frecuencia ya que habitualmente solemos olvidar que, a la hora de realizar tales trasplantes, «...debe buscarse el alma y no la semejanza exterior, mera apariencia, pues con dejarse llevar por ésta se comete el mayor yerro posible» ${ }^{59}$. De ahí que países con formas políticas externas que solemos juzgar diferentes, merced a dominar en ellos una misma clase social, un mismo «espíritu», ofrezcan muchas veces unos efectos similares (así,

58 La fórmula «soberanía de lo existente» sí llegó a acuñarse por aquellos años. En concreto, durante el debate sobre la reforma constitucional en octubre de 1844, la utilizaron Pastor Díaz y Díaz Cid para referirse a la fórmula "Cortes con Corona» incluida en el Proyecto de reforma elaborado por el Gobierno y enviado a las Cortes. Vid. Diario de Sesiones de las Cortes. Congreso. Sesiones de 30 de octubre y de12 de noviembre de 1844.

Por lo que hace a las citas de Alcalá Galiano que aparecen en el texto, ambas están tomadas de las Lecciones..., p. 74; de hecho, la lección cuarta, a la cual pertenecen tales citas, está en buena parte dedicada al tema de la soberanía.

59 Antonio Alcalá Galiano, Lecciones, pp. 13-14. Vid. también p. 46 y ss. En p. 47, abandonando el tono mucho más técnico del resto del discurso, Alcalá Galiano argumenta: «Ninguno de nosotros iría a un almacén de ropa hecha (...) y sin mirar si aquella a que alargaba la mano le venía bien o mal, se la pondría y saldría con ella muy ufano por las calles presumiendo de ir galán y airoso, y sin embargo nosotros vamos a un almacén de constituciones, alargamos la mano a una y se la vestimos a un gran pueblo (...). Lo que acabo de expresar ha sucedido, como no me cansaré de repetir, con el gobierno inglés». 
Inglaterra y Hungría, gobierno representativo el primero y gobierno absoluto el segundo, merced al semejante influjo que en ambos Estados ejercen sus aristocracias) y que, a la inversa, la adopción de una misma forma de gobierno en dos espacios sociales con una estructura de clases distinta no tenga por qué producir los deseados resultados idénticos. El caso paradigmático, en aquel momento de la historia, lo era el deseo de trasladar las formas políticas de Inglaterra a todo otro contesto con la ingenua creencia de que, por tales vías, se podría disfrutar en ellos del mismo nivel de libertad que entonces gozaban los ingleses, lo que sin duda suponía ignorar el dato que, con su peculiar ironía, ya señalara entonces Mariano José de Larra en su «Carta a un viajero inglés»: «Amigo, —diría—por acá tenemos casi todos la desgracia de no ser ingleses... ${ }^{60}$.

$\mathrm{Y}$, en cualquier caso, —algo de ello hemos adelantado hace un instanteesa misma correlación con aquel mencionado punto de partida es la que está detrás del que tal vez sea el tema más importante de todo el curso: la teoría del régimen mesocrático o, lo que es lo mismo, del gobierno de las clases medias como la forma política adecuada al tiempo en que entonces se vive. Habida cuenta de que, según ya sabemos, los intereses son la plataforma social del Estado, ganar en estabilidad política requiere crear intereses acordes a los nuevos tiempos; y, dado que esa es la tarea y la mentalidad de las nuevas clases medias, ellas deben ser el «elemento dominante». Aunque aceptando que las otras clases la moderen. En su mencionada lección tercera, dice Alcalá Galiano a sus oyentes: «Andando los tiempos, hemos llegado a época en la que las clases medias han crecido, y son lo principal, sino todo en el estado; y en estos tiempos (...) conviene que en las clases medias estén depositados el influjo y predominio» porque —continúa- «...en ellas reside la fuerza material, y no corta parte de la moral, y donde reside la fuerza está con ella el poder social, y alli debe existir también el poder político» ${ }^{61}$. Naturalmente, en el envés de esta situación está el tremendo problema de la existencia de las clases empobrecidas a las cuales el profesor del Ateneo — con pesar manifiesto ${ }^{62}$ — no acaba de reconocer ni siquiera el estatuto político de «clases moderadoras» (sí otras reducidas libertades) por si acaso ello pudiera otorgar a las mismas un papel «activo» en el modelo. Es una cuestión terrible, pero para la que el curso de Galiano - como para todo el pensamiento liberal de esa etapa- no tiene respuesta. Son los tiempos del «quien sea pobre sin su pan se lo coma» que escribiera nuestro costumbrista Antonio Flores ${ }^{63}$, y de ahí el pensamiento moderado desde cuya ideología razona Galiano no tiene voluntad ni compromiso de salir. Más aún, el acceso de esas clases menesterosas

60 Mariano José de Larra, «Carta de Fígaro a un viajero inglés», en Artículos completos, op. cit., p. 136.

61 Antonio Alcalá Galiano, Lecciones..., p. 50; p. 53 y ss. para ventajas y desventajas del gobierno de las clases medias; también p. 64 y ss.

62 Vid., en nota posterior, lo que Alcalá Galiano dice al hablar del socialismo y del avance hacia ciertas libertades de contenido social.

63 Antonio Flores, La sociedad de 1850, Alianza editorial, Madrid, 1968, p. 175. 
al Estado — piensa Alcalá Galiano- supondría la democracia, y la democracia (de nuevo aquí un tópico difícil de orillar) es el caos porque —afirma el profesor«... en pos de esto ha de venir infaliblemente el deseo de variar la sociedad; pues la muchedumbre no ba de contentarse con el poder sin sacar de él provecho» ${ }^{64}$.

Dicho lo anterior, tan sólo habría que añadir que el curso de Alcalá Galiano contiene — como ya habíamos adelantado - un tratamiento técnico inusualmente preciso y bien informado (son constantes en él las referencias concretas a la práctica inglesa, francesa y americana, que en los dos primeros casos había conocido en directo) de las múltiples cuestiones que la disciplina le plantea. Sin la intención de ser exhaustivos, ese es el caso de su teoría de la Monarquía, analizada por Galiano tanto en su diversidad de formas (aquí su preferencia por la Monarquía apoyada sobre las clases medias o Monarquía mesocrática) como en sus aspectos más funcionales (relaciones de la Corona con las Cámaras, sanción de la ley, veto absoluto o veto suspensivo, disolución regia del Parlamento, designación de Ministros, comandancia de las fuerzas armadas, nombramiento vitalicio de senadores, acceso de la mujer al trono...). Otro tanto cabría decir de su puntual consideración sobre la forma republicana de gobierno a la que dedica íntegramente la lección decimonovena ${ }^{65}$. Y, por supuesto, de su análisis sobre los sistemas electorales (tipos de sufragio, formas de votación, elecciones directas o por grados, requisitos exigibles a electores y elegibles...), sobre la estructura, prerrogativa y funcionamiento de las Cámaras (Primeras y Segundas Cámaras, sus tipos y razones, tamaño de las mismas, el Reglamento parlamentario, la Presidencia de la Cámara, el procedimiento legislativo, el régimen de las sesiones, los debates y las votaciones, el control del Gobierno, las interpelaciones, la censura y la responsabilidad de los Ministros... $)^{66}$ o sobre las libertades públicas respecto de las cuales su posición política no le permite ir más lejos pero donde su buena formación y su sensibilidad ${ }^{67}$ sí le ayudan a abrir el campo dentro de aquélla todo lo posible (libertad de los antiguos y libertad de los modernos, libertad abstracta y liberta-

64 Antonio Alcalá Galiano, Lecciones..., p. 455. Antes, en p. 60, ya había afirmado que: «Por esta razón a la muchedumbre ignorante y dependiente no puede darse parte en el gobierno de los Estados, pues dándosela, como ciega o necia haría uso de su poder dañando al público, a las clases superiores y a sí mismo».

65 A la Monarquía dedica Galiano buena parte de la lección sexta, la lección séptima y el principio de la lección octava, amén de múltiples desarrollos dispersos en otras lecciones. Para la forma republicana de gobierno, vid. la lección decimonovena.

66 De los sistemas electorales, respecto de los que Alcalá Galiano demuestra tener un exacto conocimiento relativo a los utilizados para la Cámara de los Comunes, la Cámara de Diputados francesa o la Cámara de Representantes americana, el profesor se ocupa en la lección novena y parte de la décima. Para todas las cuestiones referidas a Parlamento, Reglamento parlamentario, funcionamiento y estructura de las Cámaras, control parlamentario del Gobierno y el largo etcétera de asuntos que en el texto se mencionan, vid. las lecciones octava a duodécima. Sobre responsabilidad de los Ministros, también lección decimotercera,

67 Vid. al final de su lección decimonovena su referencia al socialismo y a la posibilidad de avanzar hacia libertades políticas y sociales extendidas a todos: «Bien está acusar de fatalistas a los que digan: Mal van las cosas, pero por fuerza han de ir así, que tal es la condición humana, y querer hacerla buena es desvarío. Pero atroz es hacer la acusación misma contra quienes no resisten que se busquen remedios, sino al revés, lo desean, lo anbelan, lo aconsejan (y) a ello se prestan...», pp. 452-453. 
des concretas, relaciones de la libertad con la igualdad, libertades civiles y libertad política, libertad de imprenta, derechos y libertades mixtos, suspensión de derechos... ${ }^{68}$. Poder municipal, Justicia, jurado, milicia nacional reforma y suspensión de las constituciones ${ }^{69}$, son —en fin - otros tantos temas tratados en el curso con idéntica extensión y minuciosidad.

Concluyamos pues. Esta es la semblanza que podemos trazar del Alcalá Galiano profesor de Derecho Constitucional del Ateneo, uno de los primeros cultivadores de la disciplina en nuestro país y sin duda el primero en abordarla con la precisión técnica, minuciosidad y rigor que acabamos de ver, también con un posicionamiento personal respecto de determinadas cuestiones que tal vez un curso desarrollado en sede universitaria —necesariamente más pedagógico y plano - no le hubiera permitido expresar. A fin de cuentas, estamos aquí — y no es poco- ante una buena síntesis del pensamiento liberal dominante en aquella etapa de la España constitucional, un pensamiento conservador si se quiere, pero expresado por quien, no sin razones, el profesor Aranguren ha querido incluir entre aquellos a quienes él llama «la derecha inteligente» ${ }^{70}$.

$$
* * *
$$

TITLE: Alcalá Galiano. The beginnings of Constitutional Law in Spain

ABstRACT: The object of this study is to make a portait of Alcalá Galiano as professor of the Constitutional Law at the Ateneo of Madrid, revising first of all the quality of the Ateneo - not the Spanish University - as unusual setting of that instruction, secondly the attractive personality of the professor and finally the content of these lessons.

RESUMEN: Estas páginas intentan realizar una semblanza de Alcalá Galiano como profesor de Derecho Constitucional en el Ateneo de Madrid, revisando en primer lugar la condición del Ateneo —no la Universidad - como marco atípico de aquella docencia, en segundo lugar la interesante personalidad del profesor y finalmente el contenido de las lecciones.

KeY words: Constitutional Law History in Spain, Antonio Alcalá Galiano, Ateneo de Madrid, Spanish Liberalism in the Nineteenth Century.

Palabras Clave: Historia del Derecho Constitucional en España, Antonio Alcalá Galiano, Ateneo de Madrid, Liberalismo en la España del siglo XIX.

FECHA DE RECEPCIÓN: 03.06.2015

FECHA DE ACEPTACIÓN: 29.07.2015

68 La teoría de las libertades está dispersa entre las lecciones cuarta, quinta y decimoséptima.

69 Para Administración territorial, lección decimoquinta; justicia y jurado, en el final de la lección trece y en la lección catorce; sobre Milicia Nacional, lección dieciséis, y respecto de reforma constitucional y suspensión de las Constituciones, lección decimoctava.

70 José Luis L. Aranguren, Moral y sociedad: la moral social española en el siglo XIX, Madrid, 1965, p. 202. 